\title{
Assessment of Ventricular Outflow Tract in Macrosomic Neonates
}

\author{
Ahmed Fetouh Abd Elrahman Elhass*, Ahmed Mohamed Ismail, Mohamed Mahmoud \\ Abd Elmohsen, Ibrahim Mohamed Abofarag
}

Department of Pediatrics and Neonatology, Faculty of Medicine, Al-Azhar University

*Corresponding author: Ahmed Fetouh Abd Elrahman, Mobile: (+20)01091577711, Email: ahmedel7ss@ gmail.com

\begin{abstract}
Introduction: Fetal macrosomia is encountered in up to $10 \%$ of all deliveries. It occurs in $15-45 \%$ of diabetic pregnancies. Factors associated with fetal macrosomia include genetics; duration of gestation; presence of gestational diabetes; high pre-pregnancy body mass index (BMI); excessive gestational weight gain and diabetes mellitus. Macrosomia is reportedly associated with neonatal morbidity, neonatal injury, maternal injury, and cesarean delivery. Moreover, shoulder dystocia, brachial plexus injury, skeletal injuries, meconium aspiration, prenatal asphyxia, hypoglycemia, and fetal death. All types of maternal diabetes are risk factors for macrosomia and can affect the foetal cardiac development in the form of Hypertrophic cardiomyopathy and congenital cardiac malformation.
\end{abstract}

Aim of work: To evaluate the cardiac changes and ventricular outflow tracts in macrosomic neonates clinically and by 2D transthoracic echocardiography.

Patients and Methods: This prospective study was carried out in NICU of Sayed Galal University Hospital on fifty macrosomic neonates' thorough detailed history, clinical examination, Chest X-ray, important laboratory investigation, two dimensional M-mode and Doppler echocardiographic examination.

Results: The fifty macrosomic neonates consisted of 29 males (58\%) and 21 females (42\%) with mean age \pm SD of $2.16 \pm 0.84$ days (range, $1-5$ days). Statistically, significant relation between inter ventricular septum diastole (IVSD) (mm) according to HbA1c level, increase IVSD with increase HbA1c level, and show statistically significant relation between inter ventricular septum diastole $(\mathrm{mm})$ and LTVOTO. When IVSD increase the incidence of LVOTO increase While TABSE decrease with the increase in IVSD. It also showed significant negative correlation between IVSD and MPI and PAP.

Conclusion: Elevated maternal HbA1c level can lead hypertrophic cardiomyopathy mainly septal hypertrophy, which increased incidence of ventricular outflow tract obstruction. These echocardiographic findings (TAPSE and MPI) seem to be a better index of the cardiac outcome of macrosomic neonates than other clinical, laboratory or radiological parameters.

Recommendations: Early echocardiographic examination for early detection of myocardial dysfunction or cardiac defect is essential in all macrosomic neonates andIDM even those without audible murmur, especially so if not improving with proper intervention. Echocardiographic indices especially TAPSE and Tei index for all macrosomic neonates to detect early cardiac changes in particular left ventricular dysfunction.

Keywords: Macrosomia, infant of diabetic mother (IDM), echocardiogram, inter ventricular septum diastole (IVSD), ventricular outflow tract obstruction, Tricuspid Annular Plane Systolic Excursion (TAPSE) and Tei index.

\section{INTRODUCTION}

The American College of Obstetricians
and Gynecologists (ACOG) defined macrosomia as birth-weight over $4,000 \mathrm{~g}$ irrespective of gestational age or greater than the 90th percentile for gestational age after correcting for neonatal sex and ethnicity ${ }^{(1)}$.

Fetal macrosomia occurs in $15-45 \%$ of diabetic pregnancies. It is most commonly observed as a consequence of maternal hyperglycemia ${ }^{(2)}$.

Factors associated with fetal macrosomia include genetics; duration of gestation; presence of gestational diabetes; high pre-pregnancy body mass index (BMI); excessive gestational weight gain and diabetes mellitus ${ }^{(3)}$. 
Morbidity and mortality associated with macrosomia can be divided into maternal, fetal, and neonatal categories. A study investigating the effects of birth weight on fetal mortality shows that higher fetal mortality rates are associated with a birth weight of greater than $4250 \mathrm{~g}$ in non-diabetic mothers and a birth weight of $4000 \mathrm{~g}$ in diabetic mothers ${ }^{(4)}$.

Approximately $3-6 \%$ of infants of diabetic mothers (IDMs) have congenital cardiac malformations, of which $40 \%$ are with HCM that may or may not be symptomatic. A major finding is hypertrophy of the ventricular and septal walls of the neonatal heart ${ }^{(5)}$.

\section{Aim of the work:}

The aim of the work is to evaluate the incidence of left and right ventricular out flow tract obstruction in macrosomic infants clinically and by 2 D transthoracic echocardiography, to find out any associated cardiac dysfunction and to detect an echocardiographic predictors affecting the outcome.

\section{PATIENT AND METHODS}

A prospective study was carried out in NICU of Sayed Galal University Hospital during a period of 12 months from September 2017 to august 2018. Our studied cases were selected by simple random method from all newborns admitted NICU in Sayed Galal University Hospital.

\section{Ethical consideration:}

- Approval of Research Ethics Committee of Al-Azhar University was obtained before conducting the study.

- Informed written consent was obtained from parents.

\section{Inclusion criteria:}

1- Term macrosomic neonate with or without evident history of maternal diabetes:

2- Gestational Age : >37 weeks.

Exclusion criteria:

- Suspected inborn errors of metabolism.

- Suspected neonatal sepsis.

Methods:

Major congenital anomalies. following:

All neonates were subjected to the

\section{1- Thorough history taking including}

Detailed perinatal history: maternal diseases and drug intake, high risk pregnancy, mode of delivery, risk factors of prematurity, labor( prolonged, obstructed, abnormal presentation), presence of meconium, antenatal ultrasound and risk factors of infection.

\section{2- Thorough clinical examination including:}

gestation age in weeks, post natal age in days, Apgar score at $1 \mathrm{~min}$ and $5 \mathrm{~min}$, anthropometric measures performed on percentile charts, general examination, cardiac examination, chest examination, abdominal examination and neurological examination, and mean arterial blood pressure.

\section{3- Laboratory investigations:}

- Complete blood count-CRP-Maternal Hbalc.

\section{4- Radiological investigation include; Chest $\mathrm{X}$ - Ray.}

\section{5- Echocardiographic examination:}

Echocardiography examinations were all performed by two pediatric cardiologists. The echocardiographic examinations were carried out using a (GE®Vivid e) cardiovascular ultrasound machine with 4-8 $\mathrm{MHz}$ electronic sector transducer. All of the examinations were carried out at the bedside and the specialist operating the echocardiograph was unaware of the newborns clinical status.

An anatomic analysis was performed by sequential segmentation, defining the general cardiac anatomy and attempting to rule out all cardiac abnormalities ${ }^{(6)}$.

Echocardiographic measurements in $\mathrm{M}$ mode were taken in accordance with recommendations made by the American Society of Echocardiography ${ }^{(7)}$, published in 1989 and adapted for preterm newborn by Silverman ${ }^{(8)}$ in 1993.

Routinely the examination consisted of M-mode and two-dimensional 
echocardiography, pulsed and continuous wave Doppler and color flow mapping.

The following were evaluated:

- Left ventricular measurements were obtained at end-systole and end diastole according to the recommendation of the American society of echocardiography.

- Left ventricular end-systolic and enddiastolic diameters and volumes (LVESD, LVESV, LVEDD, and LVEDV) were computed using the Simpson rule.

- Left ventricular ejection fraction was calculated as: \% $\mathrm{EF}=(\mathrm{EDV}-\mathrm{ESV}) / \mathrm{EDV}$.

- Left ventricular fractional shortening was calculated as: \% FS = (EDD-BSD)/EDD.

- Tricuspid annular plane systolic excursion (TAPSE).

- Interventricular septum diameter at diastole.

- Continuous Doppler over LVOT and RVOT and maximum peak gradient taken, defind by Bernouli ${ }^{(9)}$ equation.
- Pulmonary artery systolic pressure by tricuspid regurgitation (TR) peak velocity.

\section{Result}

Table (1): Demographic data of the studied group

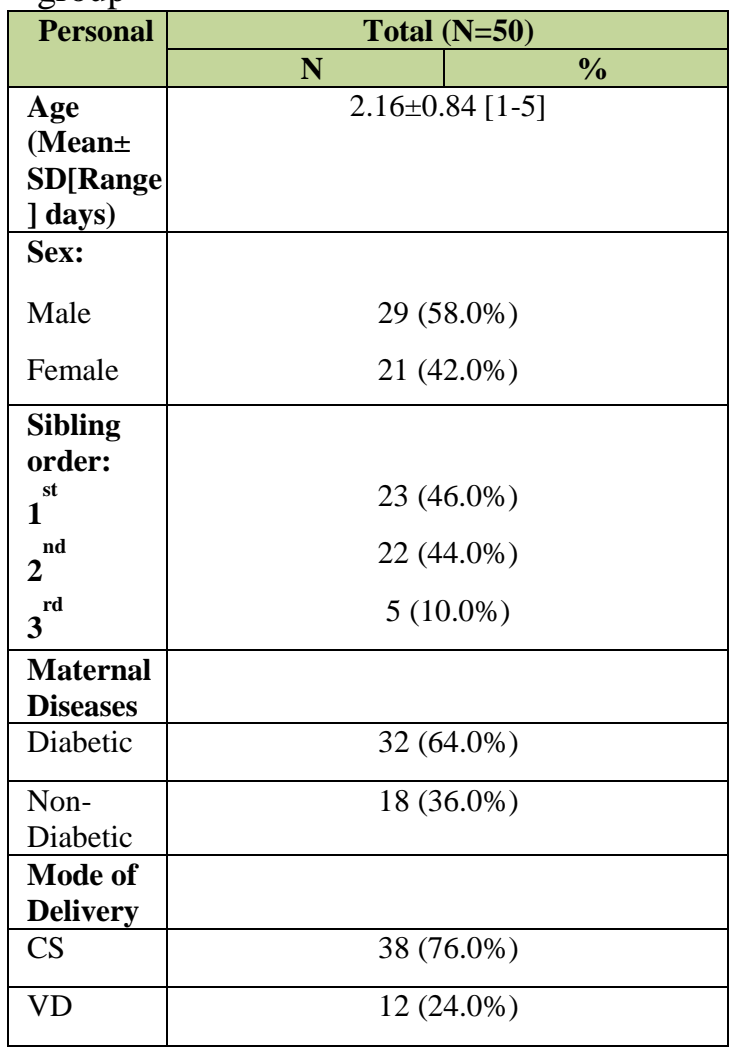

- Myocardial performance index (MPI), Tei (10) index.

Table (2): Relation between interventricular septum diastole $(\mathrm{mm})$ according to perinatal, natal and postnatal risk factors

\begin{tabular}{|c|c|c|c|c|}
\hline & \multicolumn{2}{|c|}{$\begin{array}{l}\text { Inter ventricular septum diastole } \\
(\mathbf{m m})\end{array}$} & \multicolumn{2}{|c|}{ Chi-square test } \\
\hline & $\begin{array}{c}\text { Normal } \\
(\mathrm{N}=7)\end{array}$ & $\begin{array}{c}\text { Septal } \\
\text { hypertrophy } \\
(\mathrm{N}=43)\end{array}$ & $\mathrm{x} 2$ & p-value \\
\hline \multicolumn{5}{|l|}{ Postnatal } \\
\hline HbA1c of the mo & & & \multirow{3}{*}{4.856} & \multirow{3}{*}{$0.049 *$} \\
\hline$<5.7$ & $4(57.1 \%)$ & $11(25.6 \%)$ & & \\
\hline$\geq 5.7$ & $3(42.9 \%)$ & $32(74.4 \%)$ & & \\
\hline \multicolumn{3}{|l|}{ RD-grades } & \multirow{4}{*}{7.018} & \multirow{4}{*}{$0.030 *$} \\
\hline Grade2 & $3(42.9 \%)$ & $37(86.0 \%)$ & & \\
\hline Grade3 & $2(28.6 \%)$ & $3(7.0 \%)$ & & \\
\hline Grade4 & $2(28.6 \%)$ & $3(7.0 \%)$ & & \\
\hline RBS of the baby & $59.00 \pm 18.13$ & $61.93 \pm 15.59$ & $\mathrm{~T}=0.204$ & 0.654 \\
\hline
\end{tabular}

${ }^{*} P$-value is significant 
There was statistically significant relation between inter ventricular septum diastole $(\mathrm{mm})$ according to $\mathrm{HbAlc}$ and $\mathrm{RD}$ grades.

Table (3): Relation between inter ventricular septum diastole (mm) according to echocardiography

\begin{tabular}{|l|l|c|c|c|}
\hline \multirow{2}{*}{ Echo cardiograph } & \multicolumn{2}{c|}{$\begin{array}{c}\text { Inter ventricular septum diastole } \\
(\mathbf{m m})\end{array}$} & \multicolumn{2}{c|}{ Chi-square test } \\
\cline { 2 - 5 } & \multicolumn{1}{|c|}{$\begin{array}{c}\text { Normal } \\
(\mathbf{N}=7)\end{array}$} & $\begin{array}{c}\text { Septal hypertrophy } \\
(\mathbf{N}=\mathbf{4 3})\end{array}$ & $\mathbf{x 2}$ & p-value \\
\hline PA.P (mmHg) & $43.57 \pm 15.74$ & $43.72 \pm 8.74$ & $\mathrm{~T}=0.001$ & 0.971 \\
\hline $\begin{array}{l}\text { LT.V.O.T. O } \\
\text { Present }\end{array}$ & $0(0.0 \%)$ & $9(20.9 \%)$ & & \\
Absent & $7(100.0 \%)$ & $34(79.1 \%)$ & 4.787 & $0.018^{*}$ \\
\hline $\begin{array}{l}\text { RT.V.O.T.O } \\
\text { Present }\end{array}$ & $0(0.0 \%)$ & $3(7.0 \%)$ & & 0.571 \\
Absent & $7(100.0 \%)$ & $40(93.0 \%)$ & 0.520 & 0.471 \\
\hline TAPSE (cm) & $1.12 \pm 0.08$ & $1.01 \pm 0.11$ & $\mathrm{~T}=5.181$ & $0.028^{*}$ \\
\hline MPI-TEI & $0.57 \pm 0.13$ & $0.56 \pm 0.11$ & $\mathrm{~T}=0.010$ & 0.921 \\
\hline
\end{tabular}

*P-value is significant

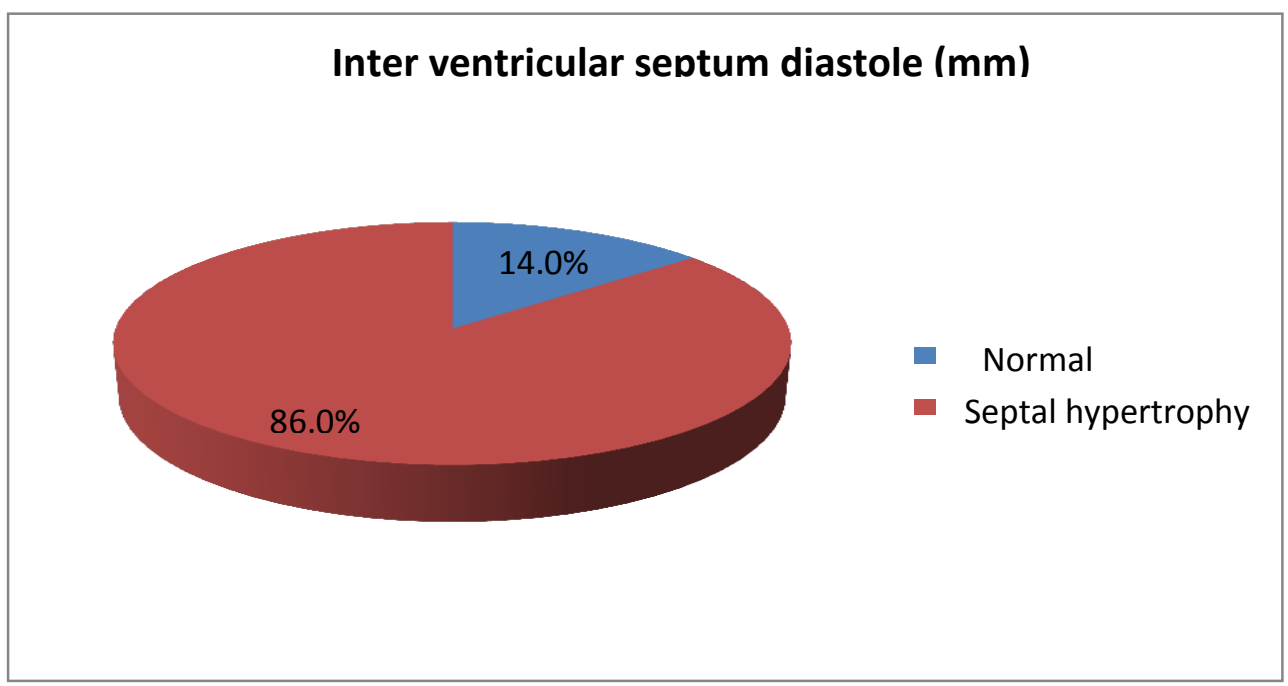

Fig. (1): Pie chart inter-ventricular septum diastole distribution of the study group.

This table shows statistically significant relation between inter ventricular septum diastole $(\mathrm{mm})$ according to LTVOTO and TAPSE.

Table (4): Relation between inter ventricular septum diastole ( $\mathrm{mm}$ ) according to oxygen support

\begin{tabular}{|c|c|c|c|c|}
\hline \multirow[b]{2}{*}{ Outcome } & \multicolumn{2}{|c|}{$\begin{array}{l}\text { Inter ventricular septum } \\
\text { diastole (mm) }\end{array}$} & \multicolumn{2}{|c|}{ Chi-square test } \\
\hline & Normal $(\mathrm{N}=7)$ & $\begin{array}{c}\text { Septal hypertrophy } \\
(\mathrm{N}=43)\end{array}$ & $\mathrm{x} 2$ & p-value \\
\hline CPAP & $2(28.6 \%)$ & $3(7.0 \%)$ & \multirow{3}{*}{7.018} & \multirow{3}{*}{$0.030 *$} \\
\hline MV & $2(28.6 \%)$ & $3(7.0 \%)$ & & \\
\hline Nasal & $3(42.9 \%)$ & $37(86.0 \%)$ & & \\
\hline
\end{tabular}

$* P$-value is significant

There was statistically significant relation between inter ventricular septum diastole $(\mathrm{mm})$ according to oxygen support. 
Table (5): Relation between LTVOTO and inter ventricular septum diastole.

\begin{tabular}{|c|c|c|c|c|}
\hline \multirow{2}{*}{ LTVOTO } & \multicolumn{2}{|c|}{$\begin{array}{c}\text { Inter ventricular septum } \\
\text { diastole }(\mathbf{m m})\end{array}$} & \multicolumn{2}{|c|}{ T-test } \\
\hline & Mean & \pm SD & $\mathbf{T}$ & p-value \\
\hline Present & 11.88 & 1.86 & \multirow{2}{*}{27.353} & \multirow{2}{*}{$<0.001 * *$} \\
\hline Absent & 8.37 & 1.82 & & \\
\hline
\end{tabular}

**p-value was highly significant.

There was statistically significant relation between LTVOTO and inter ventricular septum diastole.

Table (6): Relation between RTVOTO and inter ventricular septum diastole

\begin{tabular}{|l|c|c|c|c|}
\hline \multirow{2}{*}{ RTVOTO } & \multicolumn{2}{|c|}{$\begin{array}{c}\text { Inter ventricular septum diastole } \\
(\mathbf{m m})\end{array}$} & \multicolumn{2}{|c|}{ t-test } \\
\cline { 2 - 5 } & Mean & $\mathbf{\pm S D}$ & $\mathbf{T}$ & p-value \\
\hline Present & 12.67 & 0.58 & \multirow{2}{*}{9.922} & $0.003^{*}$ \\
\hline Absent & 8.76 & 2.12 & 9.922 \\
\hline
\end{tabular}

*P-value is significant

There was statistically significant relation between RTVOTO and inter ventricular septum diastole.

Table (7): Correlation between inter ventricular septum diastole with all parameters, using Pearson Correlation Coefficient

\begin{tabular}{|c|c|c|}
\hline \multirow{2}{*}{ Parameters } & \multicolumn{2}{|c|}{ Inter ventricular septum diastole (mm) } \\
\cline { 2 - 3 } & r & p-value \\
\hline HB A1c & 0.550 & $<0.001^{* *}$ \\
\hline Weight $(\mathrm{kg})$ & 0.017 & 0.908 \\
\hline PA.P $(\mathrm{mmHg})$ & -0.126 & 0.382 \\
\hline TAPSE (cm) & -0.281 & $0.042^{*}$ \\
\hline MPITEI & 0.171 & 0.245 \\
\hline
\end{tabular}

${ }^{*} P$-value is significant**p-value was highly significant.

Fig. (2): Scatter plot between interventricular septum diastole and HBA1c.

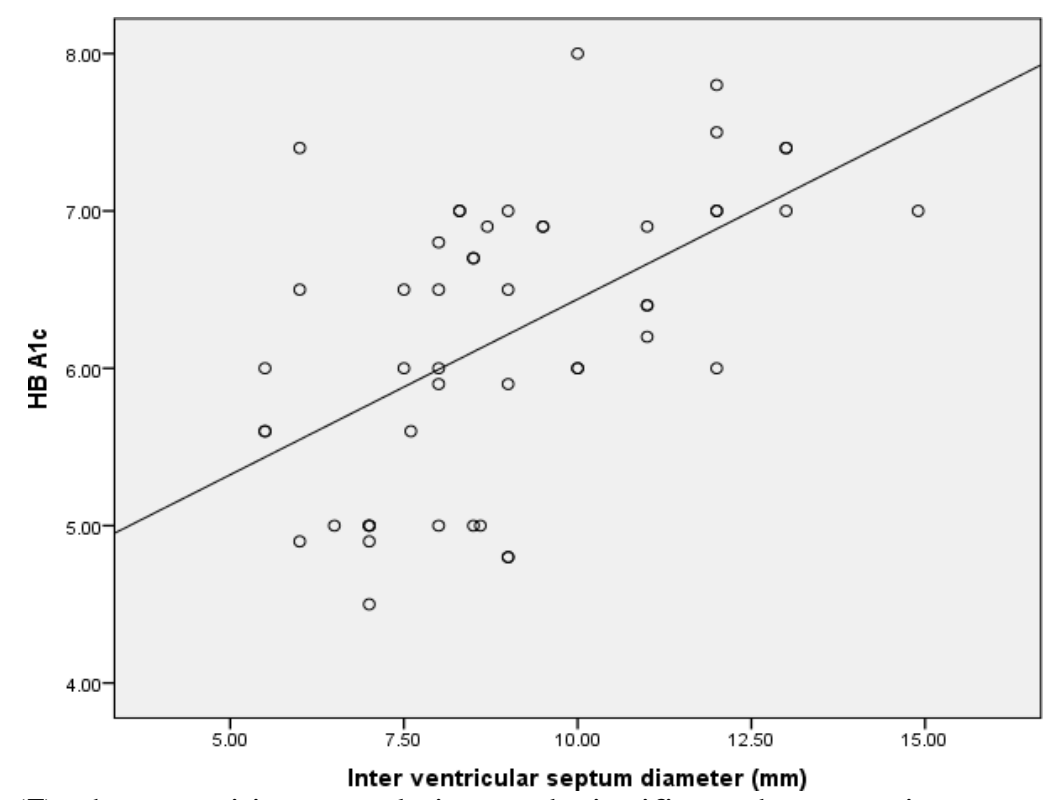

Table (7) show positive correlation and significant between inter ventricular septum diastole with $\mathrm{HbA} 1 \mathrm{c}$ and TAPSE $(\mathrm{cm})$ while negative correlation and significant MPI and PA.P. 


\section{Discussion}

Fetal macrosomia occurs in $15-45 \%$ of diabetic pregnancies. It is most commonly observed as a consequence of maternal hyperglycemia (2). Diabetes mellitus (DM) affects the fetal heart during early and late gestation ${ }^{(11)}$.

The increasing availability of echocardiography, with miniaturization technology has resulted in more wide spread use of echocardiography in NICUs around the world ${ }^{(12)}$.

Our study included fifty macrosomic neonates of those delivered in Bab El Shaireia University hospitals during the period from September 2017 to August 2018 presented to $\mathrm{Bab}$ El sheryia NICU and or outpatient clinic in the first week of life.

In the current study; macrosomic neonates were 29 males (58\%) and 21 were females $(42 \%), 23$ neonates were 1 st order sibling (46\%), 5 neonates were 2 nd order sibling (10\%) and 22 neonates were 3rd order sibling $(44 \%)$ of sibling order, and mean age $2.16 \pm 0.42$ day. at time of the study. The mean Weight was $4.24 \pm 0.35 \mathrm{~kg}$, with minimal Weight was $(4 \mathrm{~kg})$ and maximum Weight was (5.4kg).Also the mean length $50.06 \pm 0.42 \mathrm{Cm}$ with minimal Length was $(49 \mathrm{~cm})$ and maximum Length was $(51 \mathrm{~cm})$, and mean $\mathrm{HC}$ $34.86 \pm 0.45 \mathrm{~cm}$ with minimal Circumference was $(34 \mathrm{~cm})$ and maximum Circumference was $(36 \mathrm{~cm})$.

In our study, the infant of diabetic mothers with type 1 diabetes were 32 (64\%) and with GDM were $6(12 \%)$ of all macrosomic neonates, infant of non-diabetic mothers were $18(36.0 \%)$ of all macrosomic neonates, and mothers with $\mathrm{HbA} 1 \mathrm{c}<5.7$ was $30 \%$ of all cases and $\geq 5.7$ was $70 \%$ of them. While in a study by

Najafian and Cheraghi ${ }^{(13)}$ showed that only $39.5 \%$ of diabetic mothers delivered macrosomic neonates. Falavigna et al. (14) showed that all types of maternal diabetes (type1, type2 and GDM) are risk factors for macrosomia.

In the present study, delivery by CS was $(76 \%)$ of cases and delivery by VD was (24\%) of them. Also Mulik et al. ${ }^{(15)}$ showed that macrosomia is associated with a higher incidence of cesarean delivery.

In the present study, RD grade 2 was found in $80 \%$ of cases, Grade 3 was found in $10 \%$ and grade 4 was found in $10 \%$ of them.and the mean random blood sugar was $61.52 \pm 15.80 \mathrm{mg} / \mathrm{dl}$ and 6 neonates $(12.0 \%)$ had hypoglycemia. Also, Said and Manji (16), showed that the commonest neonatal complications among the macrosomic group were hypoglycemia (22.7 \%), respiratory distress $(16.5 \%)$, and birth asphyxia (14.4\%).

In present study the mean weight of macrosomic neonates was $4.24 \pm 0.35 \mathrm{~kg}$. The same Mean birth weight of macrosomic babies reported by Said and Manji ${ }^{(16)}$ which was $4.2 \pm 0.31 \mathrm{~kg}$.

In this study, clinical examination revealed that systolic murmer was present in $44 \%$ of cases and absent in $56 \%$ of them. The mean value of systolic Pulmonary artery pressure $(\mathrm{mmHg})$ was $43.70 \pm 9.78 \mathrm{mmhg}$ and $80 \%$ had pulmonary hypertention.

In present study, the mean Inter ventricular septum diastole $(\mathrm{mm})$ was $9.00 \pm 2.26 \mathrm{~mm}$. Also in this study, the prevalence of normal inter ventricular septum diastole was reported in $14.0 \%$ of cases and Septal hypertrophy was reported in $86.0 \%$ of them.

A previous study, by Ullmo et al. ${ }^{(17)}$ stated that the expected prevalence of thick IVS among fetuses of well-controlled diabetic mothers is $33 \%$ and among fetuses of poorly controlled diabetic mothers is $75 \%$.

In our study, the incidence of left ventricular outflow tract obstruction (LT.V.O.T.O) was $18.0 \%$, of all cases and right ventricular out flow tract obstruction (RT.V.O.T.O) was $6.0 \%$ of them. Also Sherif et al. ${ }^{(11)}$ stated that left ventricular mass and contractility in fetuses and neonates of diabetic mothers are exaggerated, which leads to left ventricular outflow tract obstruction due to apposition of the anterior leaflet of the mitral valve to the IVS during systole, symptomatic HCM affects $12.1 \%$ of IDMs, while it is 
diagnosed in $30 \%$ of IDMs by routine echocardiography.

In our study, the incidence of associated cardiac findings by echocardiography was patent foramen ovale (PFO) $90.0 \%$ of all cases, patent ductus arteriosus (PDA) $72.0 \%$ ventricular septal defect (VSD) 6.0\%, pulmonary stenosis (PS) $1.0 \%$ and transposition of great arteries (TGA) $2.0 \%$ of them.

In present study, TAPSE $(\mathrm{cm})$ as an index for global right ventricular myocardial function assessed by m mode echocardiography was with mean $1.02 \pm 0.11 \mathrm{~cm}$ of all cases, which is in agreement with normal value of TAPSE shown by Koestenberger et al. (18) which varied between $0.78 \pm 0.08 \mathrm{~cm}$ in neonates with a GA of $36 / 0-6$ weeks.

In our study, MPI as a cardiac function assessed by echocardiography was with mean $[0.56 \pm 0.11]$, which above the upper reference limit normal value of the Tei index showed by Karatzis et al. ${ }^{(\mathbf{1 0})}$ which is $0.39+/-0.05$ for the LV. Higher index values correspond to more pathological states with overall cardiac dysfunction.

In our study, there was statistically significant relation between inter ventricular septum diastole $(\mathrm{mm})$ and $\mathrm{HbA} 1 \mathrm{c}$, and there was statistically significant relation between inter ventricular septum diastole and left ventricular outflow tract obstruction. also Sherif et al. ${ }^{(11)}$ showed that Left ventricular mass and contractility in fetuses and neonates of diabetic mothers are exaggerated, which leads to left ventricular outflow tract obstruction due to apposition of the anterior leaflet of the mitral valve to the IVS during systole. As a result, cardiac output decreases as does the stroke volume. This effect is proportionate with the severity of septal hypertrophy.

\section{Conclusions}

- The interventricular septum diamer at diastole increase in the newborn of uncontrolled diabetic mothers, with appositive correlation to $\mathrm{HbA} 1 \mathrm{c}$ level.
- TAPSE were gradually \& significantly decreased with increasing the thickness of the IVSD, while MPI, PAP had no significant relation.

- Ventricular outflow tracts obstruction increased with increasing interventricular septum diameter.

- TAPSE as a marker for right ventricular function.

\section{Recommendations}

- We recommend early echocardiographic examination for early detection of myocardial dysfunction and cardiac defect is essential in all macrosomic and IDM neonates even those without audible murmur, especially so if not improving with proper intervention.

- Echocardiographic indices especially TAPSE and Tei index for all macrosomic neonates to detect early cardiac changes in particular left ventricular dysfunction.

- Prevention of macrosomia by controlling its risk factors can play important role in cardiac function affection.

\section{References}

1. Ng SK, Olog A, Spinks AB et al. (2010): Risk factors and obstetric complications of large for gestational age births with adjustments for community effects: Results from a new cohort study. BMC Public Health, 10:460-465.

2. Maayan-Metzger A, Schushan-Eisen I (2015): Gestational weight gain and body mass indexes have an impact on theoutcomes of diabetic mothers and infants. Acta Paediatr., 104 (11):1150-5.

3. Kim SY, Sharma AJ, Sappenfield W et al. (2014): Association of maternal body mass index, excessive weight gain, and gestational diabetes mellitus with largefor-gestational-age births. Obstet Gynecol., 123 (4):737-44.

4. Mondestin MA, Ananth CV, Smulian JC et al. (2002): Birth weight and fetal death in the United States: the effect of maternal diabetes during pregnancy. Am J Obstet Gynecol., 187(4):922-6. 
5. Mormile R, De Michele M, Squarcia U et al. (2010): And what about epidermal growth factor (EGF) as the bridge between survivin and cardiac remodeling? Int J Cardiol., 148:116-122.

6. Anderson RH, Becker AE, Freedom RM et al. (1984): Sequential segmental analysis of congenital heart disease. Pediatr Cardiol., 5:281-8.

7. Henry WA, Gardin JM and Ware J (1980): $\quad$ Echocardiographic measurements in normal subjects from infancy to old age. Circulation, 62:105461.

8. Silverman N (1993): Quantitative methods to enhance morphological information using M-mode, Doppler and cross sectional ultrasound. In: Silverman $\mathrm{N}$, editor. Paediatric echocardiography. 1st ed. London: Williams and Wilkins.

9. Darasz KH, Underwood SR, Bayliss J et al. (2002): Measurement of left ventricular volume after anterior myocardial infarction: comparison of magnetic resonance imaging, echocardiography, and radionuclide ventriculography. Int $\mathrm{J}$ Cardiovasc Imaging, 18(2): 135-42.

10. Karatzis EN, Giannakopoulou AT, Papadakis JE et al. (2009): Myocardial performance index (Tei index): evaluating its application to myocardial infarction. Hellenic J Cardiol., 50(1):605.

11. Sherif FE, Mansour GM, Mohammed SE et al. (2015): Prediction of Fetal Hypertrophic Cardiomyopathy in Diabetic Pregnancies Compared with Postnatal Outcome. Clin Med Insights Womens Health, 8: 39-43.
12. Evans N, Gournay V, Cabanas F et al. (2011): Point-of-care ultrasound in the neonatal intensive care unit international perspectives. Semmors Fetal Neonatal Medicine, 16:61-8.

13. Najafian $M$, Cheraghi $M$ (2012): Occurrence of Fetal Macrosomia Rate and Its Maternal and Neonatal Complications: A 5-Year Cohort Study. ISRN Obstet Gynecol., 2012: 353791.5.

14. Falavigna M, Schmidt MI, Trujillo J et al. (2012): Effectiveness of gestational diabetes treatment: a systematic review with quality of evidence assessment. Diabetes Res Clin Pract., 98:396-405.

15. Mulik V, UshaKiran TS, Bethal J et al. (2003): The outcome of macrosomic fetuses in a low risk primigravid population. Int $\mathbf{J}$ Gynaecol Obstet., 80(1):15-22.

16. Said AS, Manji KP (2016): Risk factors and outcomes of fetal macrosomia in a tertiary centre in Tanzania: a case-control study. BMC Pregnancy and Childbirth BMC, 16:243-248.

17. Ullmo S, Vial Y, Di Bernardo S et al. (2007): Pathologic ventricular hypertrophy in the offspring of diabetic mothers: a retrospective study. Eur Heart J., 28(11):1319-1325.

18. Koestenberger $M$, Nagel $B$, Ravekes $W$ et al. (2011): Systolic Right Ventricular Function in Preterm and Term Neonates: Reference Values of the Tricuspid Annular Plane Systolic Excursion (TAPSE) in 258 Patients and Calculation of Z-Score Values. Neonatology, 100: 85-92. 